\section{Культуры сосны на осушенных болотах в южной Карелии}

\author{
В. Н. Гаврилов ${ }^{1}$ \\ С. А. Мошников \\ Институт леса КарНЦ РАН \\ О. И. Гаврилова \\ Петрозаводский государственный университет
}

\begin{abstract}
АННОТАЦИЯ
В статье представлены результаты изучения состояния и роста 20-30-летних культур сосны обыкновенной в южной части Республики Карелия (среднетаежная подзона) на осушенных болотах разных типов. Выявлены причины, определяющие состояние и продуктивность культур сосны в различных условиях произрастания, и предложены мероприятия по оптимизации искусственного лесовосстановления на осушенных болотах.
\end{abstract}

Ключевые слова: осушенные болота, культуры сосны, обследование, состояние, продуктивность.

\section{SUMMARY}

In the paper results on study of Scots pine culture state and growth in the different types of drained mires in Southern Karelia (middle subzone of taiga) are presented. The causes defining the state and productivity of Scots pine culture in different habitats are revealed. The measures for optimization of artificial afforestation of drained mires are suggested.

Keywords: Drained mires, pine forest culture, investigation, state, and productivity.

Гидролесомелиорация в Карелии, где 37\% площади лесного фонда занято болотными лесами и болотами, является важным лесохозяйственным мероприятием, позволяющим не только повысить продуктивность древостоев, но и увеличить площадь, покрытую лесом за счет облесения болот. Лесоосушение в Республике Карелия производилось в основном в 60-70-е годы прошлого столетия, когда ежегодные объемы осушения достигали 50 тыс. га в год. Всего гидролесомелиоративные системы созданы на площади около 700 тыс. га, из которых 270 тыс. га - безлесные и слабооблесенные до осушения болота. Облесение последних осуществлялось как путем естественного заращивания, так и создания лесных культур ценных древесных пород, площадь которых к настоящему моменту составляет 72 тыс. га. Эффективность искусственного лесовосстановления зависит от многих факторов природного и производственного характера: климатических условий, подбора объектов, выбора породы, способов подготовки почвы,

${ }^{1}$ Авторы - соответственно с.н.с., вед. инженер л. $х$. Института леса КарНЦ РАН и доцент кафедры лесного хозяйства

(C) В. Н. Гаврилов, С. А. Мошников, О. И. Гаврилова, 2003 качества посадочного материала и др. Вопросы создания лесных культур на осушенных болотных почвах изучены в достаточной степени, в т. ч. и для условий Карелии, где разработаны соответствующие требования [3]. Однако, как показали проведенные ранее исследования [4], при производстве лесных культур на осушенных болотах Карелии были и просчеты. Так, искусственное облесение осушенных болот в пределах северотаежной подзоны оказалось малоэффективным вследствие неблагоприятных для роста древесных растений климатических условий. В южной части Карелии (среднетаежная подзона) успешность лесокультурных мероприятий значительно выше. Через 15-20 лет после создания культур в этих условиях формируются молодняки различного состава и продуктивности.

С увеличением давности осушения и возраста культур в фитоценозах происходят значительные изменения, связанные с усилением внутри- и межвидовой конкуренции древесной растительности, состоянием элементов гидролесомелиоративной сети, изменением свойств болотных почв. Это послужило предпосылкой проведения обследования лесоболотных культур.

Объектом обследования была выбрана часть территории Пряжинского лесхоза (бывшее Киндасовское лесничество), расположенного в южной части республики $\left(61^{\circ} 50^{\prime}\right.$ с. ш., $33^{\circ} 30^{\prime}$ в. д.) в 60 км от Петрозаводска. Район работ относится к Шуйской равнине, которая характеризуется относительно ровным рельефом с чередованием суглинистых и глинистых равнин с бедными озерными отложениями и всхломленных моренных равнин. Степень заболоченности территории довольно высокая (20-50\%, [1]). Гидролесомелиорация проведена в 1969-1972 годах. Осушение производилось открытым способом с расстояниями между каналами от 60 до 200 метров в зависимости от условий произрастания. Следует отметить высокий процент осушения болот - 77\%, расположенных в пределах лесничества.

Общая площадь лесничества по данным последнего лесоустройства (1994 г.) - 21,6 тыс. га. Гидролесомелиорация проведена на площади около 9 тыс. га., из которых половина была представлена открытыми болотами. В течение 10 лет после осушения на площади около 1500 га были созданы лесные культуры (главным образом сосны и ели). К настоящему времени, вследствие отчуждения части площадей мелиоративного фонда под сельхозпользование, площадь лесных культур составляет 1172 гектара. Это $16 \%$ от покрытой лесом площади и $41 \%$ от площади молодняков на осушенных болотах. Посадки сосны - 913,5 га.

Изучение состояния лесных культур проводилось в два этапа. В первую очередь по материалам лесоустройства 1994 года все закультивированные площади были сгруппированы по породному составу, возрасту (по пятилетиям после осушения), условиям произрастания, состоянию, на основе чего были определены маршруты натурных обследований. При работе в лесу первоначально давалась визуальная характеристика выдела, фиксировались тип леса, состояние гидролесомелиора- 
тивной сети, общее состояние культур. В наиболее характерных для выдела участках закладывались временные учетные площади, на которых производился сплошной перечет древесной растительности, определялась сохранность культур, измерялись основные показатели роста (высота, диаметр на высоте груди) по породам, характеризовались живой напочвенный покров и верхний $(0,5-0,7$ м) слой торфяной залежи. На основе данных измерений (сохранности, доли главной породы в составе молодняка, продуктивности), а также характеристики крон деревьев, наличия повреждений оценивалось состояние лесных культур с учетом условий произрастания. Культуры оценивались как хорошие, удовлетворительные, неудовлетворительные и погибшие. В дальнейшем при обобщении данных были выделены две категории: удовлетворительные и неудовлетворительные. При оценке состояния гидролесомелиоративной сети выделялись три категории: удовлетворительная, неудовлетворительная, аварийная - на основе степени зарастания дна, откосов и берм каналов растительностью, захламленности русел и по характеру (наличию) течения воды в меженный период. Аварийным состояние признавалось в случае, если имело место подтопление прилегающей к каналу территории.

Обследование молодняков искусственного происхождения производилось в июле-августе 2001 года на площади около 450 гектаров, из которых 74\% занимали культуры сосны. Следует отметить, что по данным лесоустройства сосновые посадки также преобладают $78 \%$. Согласно рекомендациям, первоочередными объектами для искусственного облесения в Карелии являются переходные болота (процент низинных болот незначителен, и они после осушения практически все отнесены к сельхозпользованию), потенциальное почвенное плодородие которых вполне достаточно для формирования высокопродуктивных хвойных молодняков при создании культур. Результаты анализа данных лесоустройства и натурных обследований свидетельствуют о том, что подбор объектов для лесокультурного освоения соответствует требованиям. Лишь около $10 \%$ площади сосновых культур созданы на бедных чисто верховых (кустарничково-сфагновых) болотах. Около половины - это культуры в условиях переходных осоково-сфагновых болот. Остальные площади представлены «граничными» бедными переходными и мезоолиготрофными условиями произрастания, отличительной особенностью которых является наличие сложной верхово-переходной торфяной залежи со слоем верхового торфа 25-75 см (на неосушенных болотах). По мнению Г. Е. Пятецкого [2], в Карелии такие болота перспективны для лесоосушения и лесовыращивания.

Как уже говорилось, лесоосушение в Карелии проводилось в основном 40-30 лет назад. На объекте исследования гидролесомелиоративные работы выполнены в период с 1969 по 1971 год. Культуры сосны создавались вплоть до 90-х годов прошлого столетия, однако основной объем посадок выполнен с 1970 по 1978 год. Возраст культур к моменту обследований составлял 22-30 лет. Технология создания культур следующая: подготовка почвы путем бороздования параллельно или пер- пендикулярно осушителям с формированием микроповышений (пластов), ручная посадка сеянцев (или саженцев) в пласты. Первоначальная густота от 3,0 до 4,5 тыс. шт. на га, в зависимости от расстояний между бороздами, шаг посадки в основном - 0,7-0,8 м. Последующие агротехнические и лесоводственные уходы за культурами проводились редко. При соблюдении требований создания культур на осушенных болотах южной Карелии через 25-30 лет формируются хвойные или смешанные хвойно-лиственные (искусственноестественные) средне- и высокополнотные (относительная полнота 0,6 и более) молодняки, строение и продуктивность которых во многом зависят от условий произрастания.

\section{СОСТОЯНИЕ И РОСТ КУЛЬТУР СОСНЫ НА ОСУШЕННЫХ ПЕРЕХОДНЫХ ОСОКОВО- СФАГНОВЫХ БОЛОТАХ}

Обследовано около 100 гектаров. Эффективность выращивания сосны в этих условиях при имеющемся уровне ведения хозяйства довольно низкая. Несмотря на высокую продуктивность формирующихся молодняков (I,8-II,5 классы бонитета), состояние культур в 70\% случаев неудовлетворительное вследствие низкой сохранности - 20-40\%. Причины тому - интенсивное естественное изреживание сосновых культур в этих условиях в возрасте 25-30 лет и конкуренция со стороны березы пушистой за свет и корневое питание. В итоге идет формирование смешанных хвойно-лиственных молодняков, в которых доля главной породы (культур сосны) в составе по запасу колеблется в пределах 40-60\%, а по густоте береза практически везде доминирует, особенно в зонах более интенсивного осушения (30-40 м от каналов). Береза в молодом возрасте (10-15 лет) растет быстрее сосны, что обусловливает угнетение последней. По полученным данным в возрасте молодняка 20-30 лет доля угнетенной сосны (растущей под кронами березы) достигает 20-30\%. Учитывая, что кроме березы основного полога (1-2 тыс. шт./га), имеется большое количество (1-8 тыс. шт./га) подроста этой породы, а также низкое товарное качество стволовой древесины березы пушистой, отметим, что для повышения хозяйственной ценности древостоев необходимы дополнительные мероприятия по уходу за составом насаждения. Другой важной причиной неудовлетворительного состояния (и гибели) культур является нарушение работы осушительной сети. В последние годы (в течение ревизионного периода) на территории лесничества произошло расселение бобров, для которых условия переходных болот являются благоприятными вследствие наличия в древостое лиственных пород. В результате их жизнедеятельности перегораживаются магистральные и собирательные каналы, повышается уровень почвенно-грунтовых вод на прилегающих территориях, вплоть до их затопления.

\section{СОСТОЯНИЕ И РОСТ КУЛЬТУР СОСНЫ НА ОСУШЕННЫХ ОСОКОВО-КУСТАРНИЧКОВО- СФАГНОВЫХ БОЛОТАХ (БЕДНЫЕ ПЕРЕХОДНЫЕ)}

Обследовано около 120 гектаров. К 25-30-летнему возрасту формируются хвойные или хвойно-лиственные 
средне- и высокополнотные молодые древостои II-III классов бонитета со сложной возрастной структурой. В данных условиях произрастания на болотах до осушения здесь произрастают сосна и береза в количестве до 500 шт./га. Доля главной породы колеблется в составе по запасу в больших пределах в зависимости от интенсивности осушения, а березы пушистой достигает $50 \%$ лишь в приканальной зоне. Это объясняется снижением плодородия верхних горизонтов почвы по сравнению с осоково-сфагновыми болотами. При этом средние показатели роста сосны и березы почти равны. Общий запас стволовой древесины в молодняках через 30 лет после осушения и создания культур здесь несколько ниже (80$100 \mathrm{~m}^{3} /$ га), чем на осоково-сфагновых болотах, хотя запас хвойной древесины выше. С удалением от каналов на 50 и более метров доля главной породы в составе по запасу увеличивается до $75-100 \%$, хотя при этом общий запас на 20-25\% ниже. Доля запаса естественной сосны может достигать $20 \%$ и выше в зоне интенсивного осушения.

Сохранность культур к 30-летнему возрасту - 35-50\%. Отпад идет в основном за счет деревьев низших ступеней толщины (меньше среднего диаметра древостоя) вследствие естественного изреживания культур и ухудшения водно-воздушного режима при выходе из строя элементов мелиоративной сети. Общее состояние культур сосны на осушенных осоково-кустарничковосфагновых болотах признано неудовлетворительным лишь на $10 \%$ обследованной площади. Причина - подтопление территории.

\section{СОСТОЯНИЕ И РОСТ КУЛЬТУР СОСНЫ НА ОСУШЕННЫХ ВЕРХОВЫХ ПУШИЦЕВО- СФАГНОВЫХ БОЛОТАХ (МЕЗООЛИГОТРОФНЫЕ)}

Характеризуются наличием верхово-переходной торфяной залежи со слоем верхового торфа в неосушенном состоянии 25-75 см. С увеличением давности осушения происходит осадка и уплотнение верхних горизонтов почвы, что позволяет при достаточном осушении корням деревьев достигать более плодородных горизонтов.

Обследовано около 60 гектаров. Через 25-30 лет после создания культур формируются, как и в предыдущем типе, смешанные хвойно-лиственные или чистые хвойные средне- и высокополнотные молодняки. Однако в этих условиях произрастания значительно меньше деревьев сосны и березы предварительной (до осушения) генерации. Снижение плодородия верхних слоев почвы и наличие почти сплошного сфагнового покрова замедляют и последующее возобновление березы пушистой. Это обусловливает увеличение доли главной породы. Культуры сосны доминируют в составе молодняков и по густоте и по запасу на всем протяжении межканального пространства. Общий запас тридцатилетнего искусственного древостоя 70-150 $\mathrm{m}^{3} /$ га, что несколько выше, чем в предыдущем типе за счет большей сохранности (сохранность культур колеблется от 30 до 80\%), доля главной породы составляет 80-100\%. Класс бонитета - I,8-III,0. По показателям роста сосна обгоняет в данных условиях березу.
Из всех обследованных участков культур на осушенных мезоолиготрофных болотах к категории неудовлетворительного состояния отнесен $21 \%$ площадей. Основная причина - подтопление территории вследствие жизнедеятельности бобров.

\section{СОСТОЯНИЕ И РОСТ КУЛЬТУР СОСНЫ НА ОСУШЕННЫХ ВЕРХОВЫХ КУСТАРНИЧКОВО- СФАГНОВЫХ БОЛОТАХ}

Обследовано около 50 гектаров. Идет образование сложных искусственно-естественных хвойных молодняков (5Сиск4С1Б). После осушения появляется береза пушистая, но ее доля в составе по количеству не превышает 10\%. Общая густота - 4,5-5,0 тыс. шт./га. Облесение кустарничково-сфагновых болот в Карелии без дополнительного минерального питания неэффективно вследствие бедности почвы. Продуктивность не превышает 5 класса бонитета. Средняя высота культур сосны в возрасте 23 лет составляет около 1,5 метра при их сохранности $50 \%$. По причине низкой продуктивности культур все площади в этих условиях отнесены к категории неудовлетворительных.

Подводя итоги анализа эффективности искусственного лесовозобновления на осушенных болотах южной Карелии (среднетаежная подзона), основанного на изучении материалов лесоустройства и результатах обследования, можно сказать, что создание культур сосны в этих условиях весьма перспективно. Через 25-30 лет после создания культур формируются средне- и высокополнотные хвойные или хвойно-лиственные молодняки, хозяйственная ценность, состояние и продуктивность которых во многом определяются условиями произрастания и состоянием элементов гидролесомелиоративной сети. Влияние последнего фактора усиливается с увеличением давности осушения при отсутствии ухода за каналами. Именно этим, видимо, объясняется различие в цифрах (по материалам лесоустройства и результатам обследования (табл.)), характеризующих состояние культур сосны. Если в 1994 году лесоустройством к категории неудовлетворительных отнесено лишь около $8 \%$ площадей (в т.ч. $0,6 \%$ - погибшие), то при обследовании в 2001 году эта цифра увеличилась до $40 \%$ (11,6\% - погибшие). Причиной того, как уже говорилось, является ухудшение водно-воздушного режима почвы вследствие подтопления (иногда и затопления) значительных территорий в результате жизнедеятельности расселившихся на объекте в последнее десятилетие бобров. Если этой проблемой не заняться всерьез в ближайшее время, то все усилия и затраты на создание искусственных молодняков в условиях осушенных болот будут напрасны.

Наиболее благоприятные условия для выращивания сосновых культур складываются в условиях осушенных бедных переходных (травяно-кустарничковосфагновых) и верховых болот со смешанной торфяной залежью (пушицево-сфагновые). 


\begin{tabular}{|c|c|c|c|c|c|}
\hline Состояние к & $\begin{aligned} \text { Іьтур } \\
\text { по }\end{aligned}$ & $\begin{array}{l}\text { сны на } \\
\text { егория }\end{array}$ & $\begin{array}{l}\text { сушег } \\
(\%)\end{array}$ & бол & $\begin{array}{l}\text { аблица } \\
\text { тах }\end{array}$ \\
\hline Источник & & тегория & состоя & ия куль & \\
\hline данных & xop. & удовл. & неуд. & погиб. & итого \\
\hline $\begin{array}{c}\text { Лесоустройство, } \\
1994 \text { г. }\end{array}$ & 58,2 & 33,3 & 7,9 & 0,6 & 100 \\
\hline $\begin{array}{c}\text { Обследование, } \\
2001 \text { г. }\end{array}$ & 49,6 & 11,2 & 27,6 & 11,6 & 100 \\
\hline
\end{tabular}

Культуры сосны (рис. 1) на 80-90\% площади на исследуемой территории через 30 лет после посадки находятся в удовлетворительном состоянии. В составе по запасу молодняков доля главной породы (культуры сосны) составляет 80-90\%, при общем запасе стволовой древесины 70-150 м³ га, в зависимости от густоты. Продуктивность молодых древостоев соответствует росту культур сосны на минеральных почвах по II,7 классу бонитета. Эти площади наиболее перспективны для лесного хозяйства, и им необходимо уделять особое внимание в целях сохранения их устойчивости и продуктивности. Особенно это касается поддержания функционального состояния гидролесомелиоративной сети. Кроме этого, целесообразно в возрасте культур 15-20 лет проведение комплексного ухода за молодня-

ками, совмещая уход за составом и прореживание в рядах культур для увеличения площади питания перспективных к выращиванию деревьев. Продуктивность смешанных хвойно-лиственных молодняков на осушенных осоково-сфагновых болотах (рис.) также высокая (класс бонитета для культур сосны - II,2). Однако в этих условиях требуется проведение лесоводственного ухода за составом молодняков в первом классе возраста. Без него ценность формирующихся древостоев снижается из-за преобладания в составе березы пушистой, которая обгоняет в росте и заглушает сосну.

\section{СПИСОК ЛИТЕРАТУРЫ}

1. Елина Г. А. Типы болот Шуйской равнины // Стационарное изучение болот и заболоченных лесов в связи с мелиорацией. Петрозаводск, 1977. С. 5-19.

2. Пятецкий Г. Е. Осушение лесных земель Карелии. Петрозаводск, 1963. $91 \mathrm{c.}$

3. Рекомендации по лесокультурному освоению осушенных болот в Карелии. Петрозаводск, 1988. 38 с.

4. Саковец В. И., Гаврилов В. Н. Лесообразовательные процессы на осушенных болотах Карелии. Петрозаводск, 1994. 102 с.

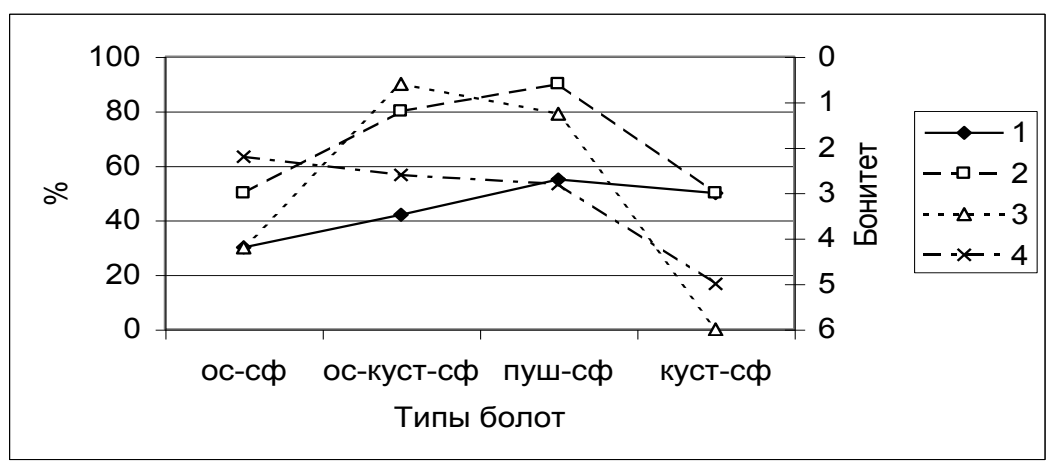

Рис. 1. Показатели состояния культур сосны на осушенных болотах юга Карелии в возрасте 25-30 лет: 1 - сохранность $(\%), 2$ - доля культур сосны в составе по запасу стволовой древесины (\%), 3 - доля площадей культур в хорошем и удовлетворительном состоянии (\%), 4 - продуктивность культур (класс бонитета) 